Chronic Obstructive Pulmonary Diseases:

Journal of the COPD Foundation

\author{
An Introduction
}

\title{
The COPD Biomarkers Qualification Consortium St George's Respiratory Questionnaire Manuscripts: Output of a Consortium to Advance Drug Development
}

\author{
Maggie Tabberer, $\mathrm{MSc}^{1 *}$ Paul W. Jones, PhD, FRCP, FERS ${ }^{1,2 *}$
}

\begin{abstract}
Abbreviations: chronic obstructive pulmonary disease, COPD; forced expiratory volume in 1 second, FEV $\mathbf{1}$; St George's Respiratory Questionnaire, SGRQ; health-related quality of life, HRQL; National Heart Lung and Blood Institute, NHLBI; COPD Biomarkers Qualification Consortium, CBQC

Citation: Tabberer M, Jones PW. The COPD Biomarkers Qualification Consortium St George's Respiratory Questionnaire manuscripts: Output of a consortium to advance drug development. Chronic Obstr Pulm Dis. 2017;4(2):109-111. doi: https://doi.org/10.15326/ jcopdf.4.2.2017.0127
\end{abstract}

\begin{tabular}{l} 
* St George's Respiratory Questionnaire Working Group Chairs for \\
the COPD Biomarkers Qualification Consortium \\
\hline 1 Research and Development, GlaxoSmithKline, Uxbridge, United \\
Kingdom \\
2 Division of Clinical Science, Institute for Infection and Immunity, \\
St George's University of London, United Kingdom \\
\hline
\end{tabular}

Address correspondence to:

Paul W. Jones, PhD

St George's University of London

Email: pjones@sgul.ac.uk

Phone: 44 (0)20 89909000

\section{Introduction}

Treatments for chronic obstructive pulmonary disease (COPD) can be aimed at different aspects of the disease, such as improving airflow, providing symptom relief, modifying or preventing exacerbations or, most ambitiously, modifying or altering the disease process. Until recently, medications for the treatment of COPD have been approved by the United States Food and Drug Administration (FDA) primarily on the basis of improvements in lung function, as measured by forced expiratory volume in $1 \mathrm{sec}\left(\mathrm{FEV}_{1}\right)$. However, there is only a weak association between $\mathrm{FEV}_{1}$ and exercise capacity, breathlessness, health status and exacerbations. ${ }^{1}$ Additionally, improvements in other aspects of the disease, such as a reduction in inflammation or extra- pulmonary consequences of the disease, may have little relationship to improvement in airway calibre.

In May 2016 the FDA issued revised guidance for the development of new treatments for COPD. For the first time the guidance included information on the use of the St George's Respiratory Questionnaire (SGRQ) to demonstrate improvements in healthrelated quality of life (HRQL) in COPD clinical trials for the development of new drugs. This guidance allows companies developing treatments to use the SGRQ with confidence. It can be used either as a co-primary endpoint, along with another measure of efficacy, or as a secondary endpoint to support changes in other endpoints to make a clinically convincing argument of efficacy.

This new guidance is the final outcome of work begun in 2010 when the FDA, in collaboration with the COPD Foundation, the National Heart Lung and Blood Institute (NHLBI) and scientists from the pharmaceutical industry and academia, conducted a workshop to survey available information that could contribute to the qualification of outcome measures that could be used in the development of new treatments for COPD. As a result of this workshop, the COPD Biomarkers Qualification Consortium (CBQC) was established to improve the speed and efficiency of clinical research by driving the approval of new drug development tools and demonstrating the validity and reliability of existing 
research tools. One of the first projects of the CBQC was qualification of the SGRQ as a measure of HRQL designed to assess health status in patients with chronic airflow limitation. ${ }^{2,3}$

Although the SGRQ was previously mentioned in FDA guidance and already accepted by European regulators, at the 2010 workshop the FDA indicated a need for analyses that demonstrated the performance properties of the SGRQ total score, specifically in terms of cross-sectional validity, longitudinal patterns and trajectories of change, and predictive validity, with the latter as an indicator of disease progression, morbidity, and mortality.

CBQC members developed an integrated database combining data from both industry- and governmentsponsored (i.e., NHLBI) studies. An analysis plan was implemented to examine the cross-sectional validity of the SGRQ when compared to other outcomes, including clinical disease characteristics and demographics, and to understand the longitudinal patterns and trajectories of change in health status by evaluating intra- and interindividual SGRQ score changes and their relationship to clinical outcomes. We also examined the predictive validity of the SGRQ for relevant outcomes such as morbidity and mortality.

The development of the database and the results of these analyses, which contributed to the endorsement of the SGRQ by the FDA, are presented in this current Journal issue as a series of 5 papers covering:

1. The characteristics of the studies included in the database and the baseline demographics of the patients and measures which determine baseline SGRQ scores.

2. The demographic determinants of change in SGRQ scores.

3. The economic determinants of change in SGRQ scores.

4. The prognostic predictive accuracy of SGRQ.

5. A definition of response and analysis based on responders to interventions.

"The members of the COPD Biomarkers Qualification Consortium dedicate the publication of this body of work on the SGRQ to the memory of John Walsh--a patient and a truly visionary leader who brought us together under a unified call for action. John never gave up on the mission of improving the lives of patients with COPD, and his passion for excellence, sense of urgency and boundless energy drove the SGRQ Working Group to this end." 


\section{References}

1. Agusti A, Calverley PMA, Celli B, Coxson et al. Characterisation of COPD heterogeneity in the ECLIPSE cohort. Respir Res. 2010;11(1):122. doi: https://doi.org/10.1186/1465-9921-11-122

2. Jones PW, Quirk FH, Baveystock CM. The St. George's Respiratory Questionnaire. Respir Med. 1991;85 (Suppl 2):25-31. doi: https://doi.org/10.1016/S0954-6111(06)80166-6

3. Jones PW, Quirk FH, Baveystock CM, Littlejohns P. A selfcomplete measure of health status for chronic airflow limitation: The St. George's Respiratory Questionnaire. Am Rev Respir Dis. 1992;145 (6):1321-1327.

doi: https://doi.org/10.1164/ajrccm/145.6.1321 